\title{
Investigating the $\mathbf{M}(\mathbf{h k l}) \mid$ Ionic Liquid interface by using Laser
}

\section{Induced Jump Temperature Technique.}

\author{
Paula Sebastian $^{\mathrm{a}}$, Elvira Gomez ${ }^{\mathrm{b}}$, Victor Climent ${ }^{\mathrm{a}}$, Juan M. Feliu ${ }^{\mathrm{a}}$. \\ ${ }^{a}$ Instituto de Electroquímica, Universidad de Alicante, Apdo. 99, 03080 Alicante, Spain \\ ${ }^{\mathrm{b}}$ Grup d'Electrodeposició de Capes Primes i Nanoestructures (GE-CPN), Dep. Ciència \\ de Materials i Química Física and Institut de Nanociència i Nanotecnologia (IN2UB), \\ Universitat de Barcelona, 08028 Barcelona, Spain
}

\begin{abstract}
KEYWORDS
Room Temperature Ionic Liquid, single crystal electrode, laser induced temperature jump technique, potential of maximum entropy, Deep Eutectic Solvent.
\end{abstract}

\begin{abstract}
The interface between several Room Temperature Ionic Liquids (RTILs) in contact with both $\mathrm{Au}(\mathrm{hkl})$ basal planes and $\operatorname{Pt}(111)$ was studied by using cyclic voltammetry and Laser Induced Temperature Jump Technique (LITJT). Three RTILs, based on the imidazolium cation and the $\left[\mathrm{Tf}_{2} \mathrm{~N}\right]$ anion were investigated: [Emmim][Tf $\left.\mathrm{T}_{2} \mathrm{~N}\right]$, $[E m i m]\left[\mathrm{Tf}_{2} \mathrm{~N}\right]$ and $[\mathrm{Bmmim}]\left[\mathrm{Tf}_{2} \mathrm{~N}\right]$. These three RTILs were selected with the aim to analyse how the balance between the different ion-ion interactions influences the interfacial properties of the $\mathrm{M}(\mathrm{hkl}) \mid \mathrm{RTIL}$ interface. It was found that the voltammetric response of the $\mathrm{Au}(\mathrm{hkl}) \mid[\mathrm{Emmim}]\left[\mathrm{Tf}_{2} \mathrm{~N}\right]$ was highly sensitive to the geometry of the active surface sites, displaying sharp spikes superimposed to a capacitive voltammetric current. Conversely, these sharp spikes disappeared when $\left.[\mathrm{Bmmim}] \mathrm{Tf}_{2} \mathrm{~N}\right]$ replaced [Emmim][Tf $\left.f_{2} \mathrm{~N}\right]$, although the capacitive voltammetric current profile was essentially
\end{abstract}


maintained. This result is most likely related to the increase of the van der Waals interactions in the $[\mathrm{Bmmim}]\left[\mathrm{Tf}_{2} \mathrm{~N}\right]$. When $[\mathrm{Emim}]\left[\mathrm{Tf}_{2} \mathrm{~N}\right]$ was analysed, the increase of the hydrogen bond interactions due to the hydrogenation of C2 (second carbon at the imidazolium ring) resulted also in the disappearance of the voltammetric spikes. The laser measurements showed that the highest values of the potential of maximum entropy (pme) in RTIL media correspond to the atomically closest packet surface structures, following the order: $\mathrm{Au}(111)>\mathrm{Au}(100)>\mathrm{Au}(110)$, in agreement with work function values. The measurement with $\mathrm{Pt}(111)$ revealed that the voltammetric profiles for this surface are featureless in all cases. However, the laser experiments revealed that solvent restructuration, as a function of both value and direction of the applied potential, is dependent on the type of cation.

Finally, the interface $\mathrm{Au}(\mathrm{hkl}) \mid$ Choline chloride:urea Deep Eutectic Solvent (DES) was also investigated by using cyclic voltammetry and LITJT. The voltammetric response of DES was also sensitive to the orientation of the Au single crystal, and the cyclic voltammograms displayed distinct sharp and characteristic features. Nevertheless, the laser response could not provide a value of the pme for the Au(hkl)|DES interface, likely due to the complex chemical structure of the DES which, in addition, strongly adsorbs on $\mathrm{Au}(\mathrm{hkl})$.

\section{INTRODUCTION}

Ionic Liquids (IL) are a relatively novel class of solvents that have been emerged as alternative to aqueous electrolytes for many different processes [1,2]. The expanding use of the ILs in the field of Electrochemistry is related to their numerous electrochemical benefits. ILs are dense ionic systems, conductive by themselves, 
without necessity of adding supporting electrolyte, and show wide electrochemical windows (between 2-6V). Then, they can be used to carry out several processes that are otherwise limited by solvent decomposition in aqueous solutions [3,4]. Furthermore, a large number of methods to prepare ILs with different chemical and physical properties have been reported, fact that provides ILs with high tuneability. In this regard, different classes of ILs have been emerging throughout the years to satisfy new application requirements [5-8].

Among other classes of ILs, Room Temperature Ionic Liquids (RTILs) have been extensively used and investigated because they show excellent both thermal and electrochemical stability for many applications. RTILs, unlike other classes of ILs, can be considered composed by discrete ions. Then, they can be treated as model ILs [5,9]. However, despite the efforts devoted to understand their electrochemical properties, there are still several unanswered questions, particularly in regard to how RTILs reorganize across the Metal|electrolyte interface. One reason to explain the lack of information regarding the interfacial properties of RTILs is the large variety of RTILs reported in the literature. Therefore, getting a rational description of these solvents is a challenging task.

RTILs properties can be explained as the result of the different ion-ion interactions that contribute to stabilize the bulk RTIL structure $[5,10]$. These bulk interactions can be: Hydrogen bond, van der Waals and coulombic in nature. In RTILs based on the imidazolium ring, the cation structure plays a key role in the stabilization of all these ion-ion interactions. In particular, the hydrogen located in the position C2 of the ring (second carbon in the ring) is of paramount importance in the balance between hydrogen bond interactions and coulombic forces. For instance, in [Emmim][Tf $2 \mathrm{~N}]$, the 
methylation of the position two in the ring increases the coulombic forces against hydrogen bond interactions, causing an increase of both melting point and viscosity parameters [11]. On the other hand, the enlargement of the alkyl chains attached to the imidazolium ring is proved to increase the van der Waals interactions [5].

The low number of reports using well-defined surfaces also explains the lack of information regarding to Metal|RTIL, especially on more catalytic model surfaces like Pt. The use of polycrystalline materials introduces uncertainty, because the contribution of the different sites cannot be discriminated. On the other hand, the use of single crystal surfaces allows relating the electrochemical response with the geometry of the specific active site, providing valuable information at the interfacial level [12,13]. Previous works carried out using $\mathrm{Au}(\mathrm{hkl})$ or $\mathrm{Ag}(\mathrm{hkl})$ in contact with RTIL, as model of ideally polarizable interfaces, have demonstrated that single crystal electrodes are powerful tools to obtain relevant information of RTIL at the surface level [14-17].

Finally, most of the RTILs are highly sensitive to moisture, thus hindering the obtention of reproducible data because the electrochemical response is very sensitive to the presence of slights amounts of water concentrated at the interfacial region [18-22]. Even though that there are RTILs classified as hydrophobic, such as the based on $\left[\mathrm{TF}_{2} \mathrm{~N}\right]$ anion [23], they still can absorb slight amounts of water with time, influencing their electrochemical properties as well as their reactivity [24-28].

In the present study, three RTILs based on the imidazolium cation and the $\left[\mathrm{Tf}_{2} \mathrm{~N}\right]$ anion in contact with $\mathrm{M}(\mathrm{hkl})$ surface electrodes are analysed: 1-Ethyl-2,3-dimethyl bis(trifluoromethlysulfonil)imide [Emmim][Tf $2 \mathrm{~N}]$, 1-Butyl-2,3-dimethyl bis(trifluoromethlysulfonil)imide $[\mathrm{Bmmim}]\left[\mathrm{Tf}_{2} \mathrm{~N}\right]$ and 1-Ethyl-2-methyl bis(trifluoromethlysulfonil)imide [Emim] $\left[\mathrm{Tf}_{2} \mathrm{~N}\right]$ (Scheme 1) While the $[\mathrm{Emmim}]\left[\mathrm{Tf}_{2} \mathrm{~N}\right]$ has the second 
position in the ring methylated, then favouring the cuolombic interactions, in the $[\mathrm{Bmmim}]\left[\mathrm{Tf}_{2} \mathrm{~N}\right]$, the enlargement of the alkyl chain in C3 would increase van der Waals interactions. Finally, $[\mathrm{Emim}]\left[\mathrm{Tf}_{2} \mathrm{~N}\right]$, which is the hydrogenated analogous of [Emmim] $\left[\mathrm{Tf}_{2} \mathrm{~N}\right]$, was selected due to the relative increase of the hydrogen bond interactions versus coulombic forces [11].

At first, the voltammetric characterization of these three RTILs in contact with Au(hkl) basal planes: $\mathrm{Au}(111), \mathrm{Au}(100)$ and $\mathrm{Au}(110)$, was carried out. Gold single crystals are polarizable surfaces that display characteristic and surface sensitive voltammetric profiles, providing valuable information of the interfacial properties [29]. Moreover, Laser Induced Temperature Jump Technique (LITJT) was employed to investigate how the species of the RTILs reorganizes as a function of the applied potential. The laser technique was demonstrated to be a valuable tool to investigate and characterize the $\mathrm{M}(\mathrm{hkl}) \mid$ aqueous solution interface [30,31], but also the $\mathrm{M}(\mathrm{hkl}) \mid \mathrm{RTIL}$ interface, as recently demonstrated [32,33]. This technique applies short laser pulses that cause a sudden increase of the temperature at the interfacial region. The change of the electrode potential is monitored during temperature relaxation after a sudden temperature jump under coulostatic conditions (constant charge, i.e., open circuit). The change of the potential electrode is mainly related with the solvent restructuration during the temperature change across the double layer region.

After gaining experience on $\mathrm{Au}$ substrates, the more reactive $\mathrm{Pt}(111)$ electrode in contact with these three RTILs was also investigated. Also, a Deep Eutectic Solvent (DES) based on the eutectic mixture between Choline Chloride and Urea was analysed in contact with $\mathrm{Au}(\mathrm{hkl})$. DESs are a relatively new class of Ionic Liquids, which are usually presented as the green and affordable alternative to replace RTILs. They share many properties with RTILs like intrinsic conductivity and sufficient thermal and 
electrochemical stability. But, at the same time, they are easier to prepare in a relative clean way [6,34]. In addition they are usually less sensitive to moisture [35]. However, chemically, they are very different to RTILs, since DESs are composed by the eutectic mixture of a bond donor proton neutral molecule (like urea) and a quaternary ammonium salt (like $\mathrm{ChCl}$ ). Because of that, the study of the $\mathrm{M}(\mathrm{hkl}) \mid \mathrm{DES}$ properties also deserves consideration to get more advances in the field of ILs. In addition, the comparison between M(hkl)|RTIL and M(hkl)|DES can be very interesting.

$<$ Scheme 1 $>$

\section{EXPERIMENTAL}

The employed working electrodes were the three $\mathrm{Au}(\mathrm{hkl})$ basal planes and the $\operatorname{Pt}(111)$, all cut from single crystal beads following the Clavilier's methodology.[12] Specific surface pre-treatment were employed for the different surfaces. Au(hkl) were flame annealed and cooled down in air. Pt(111) electrode was flame annealed and cooled down to room temperature in a reductive atmosphere of a $\mathrm{H}_{2} / \mathrm{Ar}$ mixture, due to its higher sensitivity to react with atmospheric oxygen. Then, both $\mathrm{Au}(\mathrm{hkl})$ and $\mathrm{Pt}(111)$ were transferred to the working cell. A silver wire was used as a quasi-reference electrode whereas gold or platinum wires were used as counter electrodes, depending on whether $\mathrm{Au}(\mathrm{hkl})$ or $\mathrm{Pt}(111)$ were used as working electrodes, respectively. The experiments were carried out with the electrode surface in the hanging meniscus configuration.

Cyclic voltammograms were recorded using either a $\mu$-Autolab III potentiostat (EcoChemie, Utrecht, The Netherlands) under the current integration mode or an eDAQ potentiotstat with Waveform Generator 175 (Model ER175). 
[Emmim] $\left.\mathrm{Tf}_{2} \mathrm{~N}\right]\left(\mathrm{N} 99 \%\right.$ purity), [Bmmim][Tf $\left.{ }_{2} \mathrm{~N}\right]\left(\mathrm{N} 99,9 \%\right.$ purity) and [Emim][Tf $\left.{ }_{2} \mathrm{~N}\right]$ (N99.5\% purity) were purchased from IoLiTec (<100ppm of halides). The ionic liquid was purified following the Kolb's procedure as reported hereby [20]: between 1-2 $\mathrm{mL}$ of RTILs were dried under stirring, heating $\left(\mathrm{T}<80^{\circ} \mathrm{C}\right)$ and vacuum (Pump pressure $<0.002 \mathrm{mbar}$ ) conditions during 6 hours. Then the stirring mode was stopped and molecular sieves of 3A porous size were added to the RTIL. The RTIL was then kept under vacuum, molecular sieves and heating conditions overnight. Then the IL was bubbled with an Ar stream and kept under inert atmosphere during the experiment. The Ar stream was additionally dried and deoxygenated by using a moisture/oxygen filter from Agilent company. The use of the filter was key to avoid the increase of water content in the RTIL during the experiment. The water content was measured at the beginning and at the end of every experiment, by using a Karl Fischer Titration. The measured water content was kept at 20ppm-50ppm for the [Emmim][Tf $2 \mathrm{~N}]$ and [Emim][Tf $\left.{ }_{2} \mathrm{~N}\right]$ and 50-100ppm for the [Bmmim][Tf $\left.{ }_{2} \mathrm{~N}\right]$.

Urea (Merck p.a.) and choline chloride (Across, 99\%) were mixed (molar ratio 2:1) at a low temperature $\left(\mathrm{T}<40^{\circ} \mathrm{C}\right)$. Before the experiment, the DES was kept under vacuum, stirring and at $30^{\circ} \mathrm{C}$ overnight. A thermostated cell was employed when the experiments were carried out with the DES, setting the temperature value at $40^{\circ} \mathrm{C}$.

The laser induced temperature jump experiment was performed as described in [31,36,37]. Pulses of 5 ns of the second harmonic of a Nd-YAG laser (532 nm) were used as laser source, with an energy density around $15-40 \mathrm{~mJ} / \mathrm{cm}^{2}$, a value of energy small enough to prevent the damage of the electrode. The only effect from laser irradiation is the increase of the temperature at the interface. The laser energy was measured with a piroelectric sensor head (Model M-935-10). 
To carry out the laser experiment, the electrodes were flame annealed and cooled down, and the contact with the RTIL in the meniscus configuration was made. Then, for Pt(111), a group of potential induced laser transients were measured. Afterwards, a cyclic voltammogram was recorded to ensure that the voltammetric properties of the interphase remained mostly unchanged and non-affected by surface contamination. In the case of the $\mathrm{Au}(\mathrm{hkl})$, they were flame annealed before any new laser measurement. Then, the electrode was cycled in the positive potential region where the pseudocapacitive features appeared. This specific gold surface pre-treatment was made in order to ensure that the same surface was introduced at the beginning of any potential, aiming to calculate the differences between the pme of $\mathrm{Au}(\mathrm{hkl})$ with the possible highest accuracy.

\section{RESULTS}

\subsection{Au(hkl)|RTIL interface}

Figure 1 shows the cyclic voltammetries of $\mathrm{Au}(\mathrm{hkl})$ in contact with the three RTILs, recorded at $50 \mathrm{mV} / \mathrm{s}$. Figure $1 \mathrm{~A}$ depicts the results on the three $\mathrm{Au}$ basal planes in contact with $\left[\right.$ Emmim] $\left[\mathrm{Tf}_{2} \mathrm{~N}\right]$. As we previously reported, the voltammetric behaviour of $[\mathrm{Emmim}]\left[\mathrm{Tf}_{2} \mathrm{~N}\right]$ is highly sensitive to the crystallographic orientation of the surface and the voltammograms display sharp spikes with quasi-reversible counterparts [32]. These features are superimposed to a pseudo-capacitive current region, and were assigned to order-disorder phase transitions of the RTIL species across the surface, mainly involving the $\left[\mathrm{Tf}_{2} \mathrm{~N}\right]$ anion, likely including surface reconstruction phenomena. The position of the sharp spikes with the applied potential depends on the geometry of the active site, showing the surface sensitiveness of the involved processes. 
When the RTIL cation is replaced by [Bmmim] (Fig. 1B), the sharp spikes disappear, but a similar voltammetric profile is maintained. The suppression of the sharp spikes can be related with the enlargement of the alkyl chain at the position C1 (carbon 1 in the ring). According to previous studies, the enlargement of the alkyl chain increases the van der Waals interactions that stabilizes the bulk RTIL structure, thus affecting the blank voltammograms of the RTIL. On the other hand, if a hydrogen is introduced in the second position of the imidazolium ring, i.e, [Emmim] is replaced by [Emim] (Fig. 1C), the voltammetric profile recorded in contact with $\mathrm{Au}(\mathrm{hkl})$ dramatically changes. Only minor surface sensitive features were observed in the Au(hkl)|[Emim][Tf $2 \mathrm{~N}]$ blank voltammograms. However, a common voltammetric feature appears in each of the Au basal planes, namely, the increase of the capacitive current in the potential region between $0.0 \mathrm{~V}$ and $-1.0 \mathrm{~V}$ vs Ag. These voltammetric profiles are in agreement with previous results obtained with similar RTILs containing a hydrogeneated imidazolium cation [20,38-40]. These results evidence that small changes in the cation structure highly affect the cyclic voltammogram, and that the acid hydrogen located at C2 strongly affects the surface sensitiveness of the RTIL towards the orientation of the single crystal surface.

$<$ FIGURE 1 $>$

Figure 2 shows voltammograms with increased potential limits to show the stability window of the three RTILs in contact with Au(hkl). The three RTILs display, as expected, wide electrochemical windows that ranges around 4-5 V. Both $[$ Emmim] $\left.] \mathrm{Tf}_{2} \mathrm{~N}\right]$ and $[$ Emim] $]\left[\mathrm{Tf}_{2} \mathrm{~N}\right]$ display similar voltametric windows in contact with any of the low-index $\mathrm{Au}(\mathrm{hkl})$ : slightly higher than $4 \mathrm{~V}$. In addition, a few non-surface sensitive features have appeared in both the cathodic and anodic potential regions, near to the solvent reaction/decomposition (reduction and oxidation limits). The features 
observed in the potential range between $-1.0 \mathrm{~V}$ and $-2.0 \mathrm{~V}$ could be related with the incipient solvent decomposition or with changes in the surface morphology of the single crystal (electrochemical induced etching). They could also involve the reduction of interfacial water since these features as well as the potential window are highly influenced by the presence of water as previously reported [18,22,24]. To elucidate the exact nature of these peaks, Scanning Tunneling Microscopy images of the M|RTIL interface would be necessary $[14,41]$. Turning back to the voltammetries showing the potential window, a reduction peak centered at $1.0 \mathrm{~V}$ appears after oxidizing the RTIL. This peak is likely related to the reduction of the gold oxide formed in the positive scan, due to the presence of interfacial water that concentrates at the surface after strong potential polarization [41], a phenomenon also observed in other interfaces [42].

While $\left[\right.$ Emmim] $\left[\mathrm{Tf}_{2} \mathrm{~N}\right]$ and $[\mathrm{Emim}]\left[\mathrm{Tf}_{2} \mathrm{~N}\right]$ display similar voltammetric windows in contact with $\mathrm{Au}(\mathrm{hkl}),[\mathrm{Bmmim}]\left[\mathrm{Tf}_{2} \mathrm{~N}\right]$ displays a wider voltammetric window, particularly, on $\mathrm{Au}(100)$ (Fig. 2B) for which the voltammetric window is higher than 6V. This demonstrates that the cation structure has a strong influence in the electrochemical stability of the RTIL. In particular, the length of the alkyl chain increases the electrochemical stability of the system. Cyclic voltammograms obtained on $[\mathrm{Bmmim}]\left[\mathrm{Tf}_{2} \mathrm{~N}\right]$ also displayed similar voltammetric features in both the topmost negative and positive potential regions, revealing that similar processes could take place in the three RTILs, near to the onset of solvent decomposition.

$<$ FIGURE 2>

After carrying out the voltammetric characterization, the LITJT was employed to get deeper insights on the $\mathrm{Au}(\mathrm{hkl}) \mid \mathrm{RTIL}$ interface. First, the laser induced potential transients were recorded on $\mathrm{Au}(\mathrm{hkl}) \mid[\mathrm{Emim}]\left[\mathrm{Tf}_{2} \mathrm{~N}\right]$. Figure 3 shows these transients, recorded at different applied potentials, as well as the position of the calculated pme 
relative to the characteristic voltammetric features for $\mathrm{Au}(111)$ (Fig. 3A), $\mathrm{Au}(100)$ (Fig. 3B) and $\mathrm{Au}(110)$ (Fig. 3C). For each $\mathrm{Au}(\mathrm{hkl})$, the laser transient had positive sign at sufficiently positive applied potentials. By decreasing the applied potential, the magnitude of the transient decreased until it changed into negative values. These results suggest that, at sufficiently high applied potentials, the plane closer to the surface is richer in anions. By decreasing the applied potential, the cation would replace the anion until the population of cations at the plane close to the surface overcomes the population of anions, thus obtaining a negative laser transient. At the potential of zero transient, the same population of cations and anions would be present at the interface. In comparison to previous studies, [32] we can consider this potential as the potential of maximum entropy of the metal/RTIL interphase.

Interestingly, the calculated pme for the three gold basal planes in contact $\left[\right.$ Emim] $\left[\mathrm{Tf}_{2} \mathrm{~N}\right]$ followed the order: pmeAu(111)>pmeAu(100)>pmeAu(110). This results are in agreement with the results obtained in $\mathrm{Au}(\mathrm{hkl})$ in contact with the methylated [Emmim] $\left[\mathrm{Tf}_{2} \mathrm{~N}\right]$ in our previous report [32]. The pme values for each basal plane in contact with $[\mathrm{Emim}]\left[\mathrm{Tf}_{2} \mathrm{~N}\right]$ were: -0.68 for $\mathrm{Au}(111),-0.74 \mathrm{~V}$ for $\mathrm{Au}(100)$ and $1.00 \mathrm{~V}$ for $\mathrm{Au}(110)$ (see Fig. 3). It is important to remark that the accuracy of these results is highly affected by the purity of the RTIL, i.e., by the water content, because a slight increase of the water content shifts the pzc to more negative potentials, as reported in previous works [18]. To carry out these experiments with the highest possible reproducibility (with a reproducibility in the range of $\pm 50 \mathrm{mV}$ ), water content was kept constant and below 20-50 ppm during the time of the experiment, using for that a high purity and dry Ar stream to bubble the RTIL to ensure inert atmosphere. The reproducibility is in the range of $\pm 50 \mathrm{mV}$, less accurate than in classical electrolytes 
[43]. This could be due to the small difference in the specific water content measured between independent experiments [18].

Finally, it is important to clarify that $\mathrm{Au}(\mathrm{hkl})$ surface reconstruction induced electrochemically depends on the applied potential. It is well known that, in aqueous solution, at sufficiently low applied potentials, $\mathrm{Au}(\mathrm{hkl})$ surfaces are reconstructed while the reconstruction lifts at sufficiently positive applied potentials, higher than the pzc. Since the employed methodology includes a step where the electrode potential is held at a constant value, the most stable structure, either reconstructed or un-reconstructed, will be obtained at each potential, depending on the thermodynamic properties of the surface. Because of that, future work that investigates in more detail the reconstruction phenomena in RTIL media is necessary. Microscopic techniques would reveal the potential range at which the reconstructed surface is lifted, as well as its dependence with the specific nature of the RTIL.

Despite the sensitivity to the experimental conditions, this result highlights that the pme for low-index $\mathrm{Au}(\mathrm{hkl})$ in contact with $[\mathrm{Emim}]\left[\mathrm{Tf}_{2} \mathrm{~N}\right]$ follows the trend observed with the work function values in vacuum or the pzc values in aqueous solution in absence of ionic specific adsorption [32]. The highest pzc value corresponds to surfaces with higher atomic-coordination number: $\mathrm{Au}(111)>\mathrm{Au}(100)>\mathrm{Au}(110)$. Furthermore, this result also agrees with the previous results obtained in $[\mathrm{Emmim}]\left[\mathrm{Tf}_{2} \mathrm{~N}\right]$, with slight discrepancy between the pme differences in each media due to the different solventsurface interaction [32]. These results also validate the use of laser-induced temperature jump technique to investigate the $\mathrm{M}(\mathrm{hkl}) \mid \mathrm{RTIL}$ because it provides valuable information of the RTIL solvent network structuration as a function of the applied potential.

Unfortunately, the measurement of the pme in $[\mathrm{Bmmim}]\left[\mathrm{Tf}_{2} \mathrm{~N}\right]$ was only possible for $\mathrm{Au}(111)$ but not for $\mathrm{Au}(100)$ or $\mathrm{Au}(110)$. For the other surfaces, the sign of the transient 
was still positive, or close to zero, at the lowest potential limit previous to the onset of solvent reduction, suggesting that the pme lies outside the potential window of stability of the solvent. One possible reason for this result is that the water content in this RTIL was higher than in $[\mathrm{Emim}]\left[\mathrm{Tf}_{2} \mathrm{~N}\right]$, around $100 \mathrm{ppm}$, despite that the same purification procedures were applied to both RTILs. In this situation, the presence of water highly affects the free charge distribution of the solvent and shift the pme value as previously reported [18]. The fact that the pme of $\mathrm{Au}(111)$ could be measured reinforces the idea that $\mathrm{Au}(111)$ has the highest pme value also in $[\mathrm{Bmmim}]\left[\mathrm{Tf}_{2} \mathrm{~N}\right]$, and then it can be measured even in an excess of water. Therefore, only for this surface, the potential window would be sufficiently wide to register the sign change in the laser induced potential transient before the beginning of the solvent reduction. These results seem to highlight that the interfacial properties of the RTIL are highly sensitive to the presence of very low amounts of residual water. Water concentrates at the interfacial region, especially in the less compact structures, even in a rich-RTIL environment. (100 ppm is equivalent to $0.01 \%$ of mass of water in the total mass of RTIL or $5.5 \cdot 10^{-3}$ mol per $\mathrm{kg}$ of RTIL), and modifies the dynamics of solvent restructuration as previously reported $[21,44]$. To conclude, the presence of water deserves further consideration since it may have huge implications in the electrocatalytic properties of a metal electrode in RTIL. $<$ FIGURE 3>

Figure 4 compares the recorded laser potential transients as well as the calculated pme of $\mathrm{Au}(111)$ in contact with: [Emmim] $\left[\mathrm{Tf}_{2} \mathrm{~N}\right]$ (Fig. 4A), [Bmmim] $\left[\mathrm{Tf}_{2} \mathrm{~N}\right]$ (Fig. 4B) and [Emim][Tf $2 \mathrm{~N}]$ (Fig. 4C). Figure 4D shows that the difference between the pme of $\mathrm{Au}(111)$ in contact with the three above-mentioned RTILs is small. The smallest value was obtained for $[\mathrm{Bmmim}]\left[\mathrm{Tf}_{2} \mathrm{~N}\right]$. However, as the water content can slightly vary from one RTIL to another one, we cannot conclude that the relative small potential difference 
between the pme values for $\mathrm{Au}(111) \mid\left[\right.$ cation] $\left[\mathrm{Tf}_{2} \mathrm{~N}\right]$ is due to the residual water content in each RTIL or to the specific nature of the RTIL cation. Despite this uncertainty, the analysis of the $\mathrm{Au}(111) \mid \mathrm{RTIL}$ with the laser technique revealed that the pme is located at slightly more negative potentials than the potential region in which the characteristic voltammetric features appear in any RTIL (Fig. 4D). This result supports that the anion highly contributes in the interfacial processes revealed as voltammetric features because the electrified interface would be richer in anions at potential values higher than the pme. Still, we need to consider that the cation in the RTIL is also present in a region close to the surface, although in less proportion than the anion at potential values > pme, to explain the influence of the chemical structure of the cation in the voltammetric profile, in this potential region (Figure 1). Hence, we can attribute such sensitivity to the cation structure to the different balance between surface-ion and anion-cation interactions in the RTIL. Recently, Bing Wei Mao's research group have investigated the interfaces between $\mathrm{Au}(111) \mid[\mathrm{Emmim}]\left[\mathrm{Tf}_{2} \mathrm{~N}\right]$ and $\mathrm{Au}(111) \mid[\mathrm{Emim}]\left[\mathrm{Tf}_{2} \mathrm{~N}\right]$ combining in-situ STM and AFM. According to STM and AFM measurements, the different cyclic voltmmograms recorded in each RTIL would be related with the different interactions between the $\mathrm{Au}(111)$ surface and the RTIL, but also with the different interactions between anion-cation in each RTIL, which affects the ionic layering and restructuration dynamics at the region near the surface [45].

$<$ FIGURE 4 $>$

\subsection{Pt(111)|RTIL interface}

The $\operatorname{Pt}(111) \mid\left[\right.$ cation] $\left[\mathrm{Tf}_{2} \mathrm{~N}\right]$ was also investigated. Figure 5 shows the blank cyclic voltammograms in the capacitive region (potential range between -1.0 and $1.0 \mathrm{~V}$ vs $\mathrm{Ag}$ and the potential windows of the three ionic liquids in contact with $\operatorname{Pt}(111)$. The voltammetric profile in the capacitive region is, in any case, featureless (red line in Fig. 
5) [25]. Contrary to $\mathrm{Au}(\mathrm{hkl}), \operatorname{Pt}(111)$ does not display any surface sensitive

voltammetric feature, thus the cyclic voltammogram provides little information of the processes taking place at the electrified interface. The voltammetric window under relatively high dry conditions (water content between 20-100ppm) is higher than $3.5 \mathrm{~V}$, approaching to $4 \mathrm{~V}$ for both $[\mathrm{Emmim}]\left[\mathrm{Tf}_{2} \mathrm{~N}\right]$ and $[\mathrm{Emim}]\left[\mathrm{Tf}_{2} \mathrm{~N}\right]$, in agreement with results obtained with $\left[\right.$ Emmim] $\left[\mathrm{Tf}_{2} \mathrm{~N}\right]$ under glove box conditions [25]. The voltammetric window of $[\mathrm{Bmmim}]\left[\mathrm{Tf}_{2} \mathrm{~N}\right]$ is the largest one and approaches to $4.5 \mathrm{~V}$. Then, the electrochemical stability trend with the cation structure is analogous to the observed using Au(hkl) single crystal electrodes. The enlargement of both cathodic and anodic potential limits causes an increment of the voltammetric current in the capacitive region. In addition, the voltammetric profile displays a few non-surface sensitive peaks whose current intensities increase by enlarging both the cathodic and anodic potentials limits. Further oxidation of the solvent causes the appearance of reduction peaks in the reverse scan, centered at $0.50 \mathrm{~V}$. We relate these peaks with the presence of interfacial water, as observed on $\mathrm{Au}(\mathrm{hkl})$ electrodes [24-26]. The platinum surface co-oxidizes with the solvent decomposition favoured by the presence of water. Then, the Pt- $\mathrm{O}_{\mathrm{x}}$ reduce in the reverse scan. Interestingly, this peak splits in two peaks when the employed ionic liquid is $[\operatorname{Emim}]\left[\mathrm{Tf}_{2} \mathrm{~N}\right]$, and thus it could involve the reduction of different $\mathrm{Pt}-\mathrm{O}_{\mathrm{x}}$ but also other reductive processes related with the specific nature of the cation (reduction of the solvent decomposition products). In the low potential region, the reduction of the solvent causes the appearance in the reverse scan of a small oxidation peak, also related with the slight residual amount of water [25]. To conclude, we relate all these voltammetric peaks with the presence of residual water but also with traces of oxygen in the environment because they do not appear or hardly appear when the experiment is carried out in a glove box and the water content is less than 5-10ppm 
$[31,36]$. Unfortunately, to set up the LITJT experiments, which are the core of this work, in a glove-box controlled atmosphere require difficult adaptations that are not available in our lab at present.

$<$ FIGURE 5 $>$

Figure 6 shows the corresponding laser transients obtained in each RTIL, by applying different potentials from positive to negative values (Fig. 6A: [Emmim] $\left[\mathrm{Tf}_{2} \mathrm{~N}\right]$. Figure 6B: $\left[\right.$ Emim] $\left[\mathrm{Tf}_{2} \mathrm{~N}\right]$. Figure 6C: $\left[\mathrm{Bmmim}^{\mathrm{B}}\right]\left[\mathrm{Tf}_{2} \mathrm{~N}\right]$, left side). In the three RTILs, the laser transients decrease in magnitude until the laser transients change sign, meaning that the cation has replaced the anion in the vicinity of the metal. Figure 6 also reports the values of the thermal coefficients $(\partial \Delta \phi / \partial T)_{q}$ (up to a proportionality constant), at the different values of the applied potential. These values are obtained from the slopes of the laser induced potential transients plotted as a function of $1 / t^{1 / 2}$, as reported previously [33].

Red circles in Figure 6 (Fig. 6A, B and C, right column) are the experimental linearized slopes (thermal coefficients) at any applied potential, when the applied potential was scanned from positive to negative values (p-n direction), while black squares are those measured when the applied potential was changed from negative to increasingly positive values (n-p direction). It must be reminded that for these measurements the potential is stopped at each value during several minutes. Figure 6 shows that the sign and magnitude of the slopes derived from the laser transients depend not only on the applied potential, but also on the scan direction. According to this, the restructuration of the solvent network in RTIL does not display a reversible behavior and a single value of the pme cannot be obtained. Instead of that, a relatively narrow potential range in which the pme would be located is reported. 
Both $\left[\right.$ Emmim] $\left[\mathrm{Tf}_{2} \mathrm{~N}\right]$ and $[\mathrm{Bmmim}]\left[\mathrm{Tf}_{2} \mathrm{~N}\right]$ display hysteresis in the way the sign and/or magnitude of the thermal coefficients decrease by reversing the potential scan (Fig. 6A and 6B, right sides). [Emmim][Tf $\left.{ }_{2} \mathrm{~N}\right]$ shows the most abrupt hysteresis behavior (Fig. 6A) and around $600 \mathrm{mV}$ separates both obtained values of pme: pme ${ }_{\mathrm{n}}<$ pme $_{\mathrm{n}-\mathrm{p}}$ (see Fig. 6A, right side). The separation between both pme is around $200 \mathrm{mV}$ in $[\mathrm{Bmmim}]\left[\mathrm{Tf}_{2} \mathrm{~N}\right]$. This result highlights that the dynamics of solvent restructuration depends on the cation structure. The increase of the alkyl chain in the imidazolium ring diminishes the irreversibility of solvent structuration. One tentative explanation to these results is that the enlargement of the alkyl chain decreases the interactions between ions, thus enhancing the exchange between anion and cation in the layered interfacial region. Other possibility is that the hysteresis behavior is related with a strong interaction between $\operatorname{Pt}(111)$ and the cation. Once the cation replace the anion, an overpotential is required to replace again the cation and increase the anion concentration at the interfacial region. The enlargement of the alkyl chain would, then, affect in some way the interaction energy between $\operatorname{Pt}(111)$-cation but also cation-anion.

$[$ Emim $]\left[\mathrm{Tf}_{2} \mathrm{~N}\right]$ also displays non-reversible behavior with the direction of the applied potential, but the dependence of the thermal coefficients with the potential scan is a bit different. The values of the slopes for the different scanning directions cross to each other (Fig. 6C right side). Furthermore, the $\mathrm{pme}_{\mathrm{p}-\mathrm{n}}>\mathrm{pme}_{\mathrm{n}-\mathrm{p}}$, with a potential difference of around $100-150 \mathrm{mV}$. This result supports that in $[\mathrm{Emim}]\left[\mathrm{Tf}_{2} \mathrm{~N}\right]$, the replacement of the cation by the anion seems to be less impeded than in the former, triply alkylated, cations. Thus, the methylation of the position 2 in imidazolium ring not only increases the viscosity and decrease the melting point, but also reduce the solvent restructuration dynamics or increase the interactions between Pt and the cations or cation-anions. These results agree with the recent studies carried out by Bing Wei Mao's group, who 
investigated the double layer structure of $\mathrm{Au}(111) \mid[\mathrm{Emmim}]\left[\mathrm{Tf}_{2} \mathrm{~N}\right]$ and $\mathrm{Au}(111) \mid[\mathrm{Emim}]\left[\mathrm{Tf}_{2} \mathrm{~N}\right]$ by using AFM [47]. They supported that the methylation of the second position in the ring caused an increase of the cation-anion interactions resulting in a more layered distribution of the ions in the double layer region. The more layered ionic network would then explain the slower solvent reorganization dynamics in $\left[\right.$ Emmim] $\left[\mathrm{Tf}_{2} \mathrm{~N}\right]$ compared with $[$ Emim $]\left[\mathrm{Tf}_{2} \mathrm{~N}\right]$.

The above results agree with previous reports that employed spectroscopic techniques like SFG (Sum Frequency Generation) [47], SEIRAS (Surface enhanced Infrared Spectroscopy) [48], Raman spectroscopy [49] or AFM [50] to investigate the dynamics of solvent restructuration in RTILs. They demonstrated that RTILs undergoes multilayer arrangement and the ionic ad-layer restructuration is non-reversible and dependent on the direction of the applied potential [32]. In conclusion, previous works and the reported results here show that solvent restructuration dynamics in RTIL is nontrivial and depends on several factors: applied potential, scan potential and structure of the cation of RTIL.

Finally, there is still a remaining question: the influence of residual water at the ppm level in the dynamics of solvent restructuration of RTILs in contact with $\operatorname{Pt}(111)$. Experiments under glove box and near to extremely dry conditions will be strongly necessary in the future to allow a deeper analysis of the role of interfacial water. $<$ FIGURE 6>

\subsection{Au(hkl)|DES interface}

In the section 3.1, Au(hkl) surfaces were demonstrated to be excellent electrodes to characterize the interfacial properties of the $\mathrm{M}(\mathrm{hkl}) \mid \mathrm{IL}$ interface. From voltammetric experiments information about surface sensitive and/or it was established that the response towards the laser perturbation depends on the surface orientation. In this 
section, the interface $\mathrm{Au}(\mathrm{hkl}) \mid \mathrm{DES}$ was also investigated combining both cyclic voltammetry and laser induced temperature jump induced technique. The selected DES was the eutectic mixture between $\mathrm{ChCl}$ and urea (1:2 molar ratio). Figure 7 shows the blank cyclic voltammograms of the $\mathrm{Au}(\mathrm{hkl})$ (left side) recorded in the pseudo-capacitive region of the $\mathrm{M}(\mathrm{hkl}) \mid \mathrm{DES}$. Au(111)|DES and Au(100)|DES cyclic voltammograms (Fig. 7A and 7B, left side) display several characteristic features and sharp, surface sensitive, couples of peaks which were labelled as a-a', b-b', c-c'... in Figure 7. The voltammetric profiles are complex and, with the aim to figure out the origin of the different peaks, several cycles with different cathodic potential limits were recorded. Neither for $\mathrm{Au}(111)$ nor for $\mathrm{Au}(100)$, the peaks shift by changing the potential limits unlike for $\mathrm{Au}(111) \mid[\mathrm{Emmim}]\left[\mathrm{Tf}_{2} \mathrm{~N}\right]$ for which the voltammetric profile is less stable and depends on the potential scan window [29,32]. However, the intensity of the voltammetric peaks in DES is dependent on the lower potential limit. These peaks could be related to order-disorder phase transitions involving the species of the DES. In particular, they likely involve the chloride anion, since this DES is highly concentrated in chloride (5M). Nevertheless, some of these peaks could also be related with surface reconstruction/un-reconstruction processes [51][29]. As above-mentioned, the reconstructed structure on $\mathrm{Au}(\mathrm{hkl})$ lifts at sufficiently positive potentials at which the anion adsorbs on the surface, inducing the un-reconstructed structure. In particular, the feature labelled as $a$ in figure 7B, corresponding to Au(100)|DES reminds the feature recorded in aqueous solution in the presence of chloride or sulfate at $0.40 \mathrm{~V}$ vs SCE [29,52]. This feature was assigned to the lifting of the reconstruction, i.e., the transition of $\mathrm{Au}(100)-(\mathrm{hex})$ to $\mathrm{Au}(100)-(1 \mathrm{x} 1)$. In this DES, the peak labelled as $a$ in the $\mathrm{Au}(100) \mid \mathrm{DES}$ characteristic voltammogram (Fig. 7B), decreases in magnitude by increasing the cathodic potential limit (moving it to lower, more negative values). In 
addition, it is quite irreversible, reinforcing the hypothesis that this feature is actually linked with the lifting of the electrochemically induced surface reconstruction of $\mathrm{Au}(100)$ in contact with DES.

The voltammetry of the $\mathrm{Au}(110) \mid \mathrm{DES}$ interface displays several characteristic broad bands in the potential range between $-0.8 \mathrm{~V}$ and $0.6 \mathrm{~V}$, and the magnitude of the current densities depends also on the lower potential limit. However, unlike Au(111) and $\mathrm{Au}(100)$, sharp spikes have not appeared in the voltammetric profile. An explanation for the absence of sharp spikes for $\mathrm{Au}(110)$ is that the species of the DES would require large domains with well-ordered terraces to adsorb and form two dimensional ordered structures. The higher atomic roughness of the (110) surface breaks the long-range condition for the surface order-disorder transition in the present case. Finally, the voltammetric potential window of solvent stability are only around 2-3V (not shown) and do not display other surface sensitive features, as demonstrated in [52]. As expected, DES are less electrochemically stable than the previous RTILs.

After carrying out the voltammetric characterization, the potential laser transients were recorded for the $\mathrm{Au}(\mathrm{hkl}) \mid \mathrm{DES}$ interface in the potential range between $-0.90 \mathrm{~V}$ to $0.60 \mathrm{~V}$. Unlike for the RTIL, the laser transients were always negative in the complete investigated potential range for the interfaces Au(111)|DES and Au(100)|DES (Fig. 7A and $7 \mathrm{~B}$, right side). In addition, the laser response was complex and the laser transients at sufficiently positive applied potentials were bipolar. The bipolar behavior of the electrode potential change in the microsecond time scale suggests that processes with different rate are overlapped. For instance, the solvent restructuration or double layer potential drop with specific adsorption of the DES [43]. Thus, unfortunately, the calculation of the pme in this media and with this technique was not possible. We tentatively explain the negative sign of the transients assuming that the large amount of 
chloride in DES dominates the response of the electrode potential after the laser firing. The specifically adsorbed chloride is likely to retain some fractional charge that will induce a negative electric field (pointing towards the surface) in the interfacial region [53]. Other possibility is that the super-equivalent chloride adsorption, caused by the high chloride concentration at the interface at high surface polarization, reverses the sign of the surface charge [53]. The chloride adsorption should be favored at potentials >pzc, but with these data is not possible to identify the onset potential for the chloride adsorption as well as the rest of species of the DES.

The potential-laser transients obtained for the Au(110)|DES are singular. They even display a behavior even more complex than those obtained for $\mathrm{Au}(111)$ and $\mathrm{Au}(100)$. In $\mathrm{Au}(110)$, the laser transients are markedly bipolar. The fastest process displays a positive potential change, while the slowest response is negative. This result reinforces the idea that the introduction of steps on the surface affects dramatically the reestructuration of the DES solvent and, therefore, $\mathrm{Au}(110)$ exhibits completely different interfacial properties than $\mathrm{Au}(111)$ and $\mathrm{Au}(100)$. From these data, we can not provide more explanation about the potential laser transients profiles.

In conclusion, DESs are complex electrolytes. Different interfacial processes overlap at the same time due to their characteristic chemical structure. Because of that, RTILs can be better models to get rational description of ILs. However, due to the increasing interest in using DESs for a wide field of applications, more work is encouraged to do with the aim to get a deeper understanding of their properties at the interfacial level.

$<$ FIGURE 7>

\section{CONCLUSIONS}


In the present paper, the $\mathrm{M}(\mathrm{hkl}) \mid \mathrm{IL}$ interface was investigated using cyclic voltammetry and laser-induced temperature jump technique. At the beginning, three RTILs based on the imidazolium ring and the $\left[\mathrm{Tf}_{2} \mathrm{~N}\right]$ anion were studied, and the effect of the cation structure was analyzed in detail. Three different cations were compared: two triple alkylated cations ([Emmim] and [Bmmim]) and a third one with the position C2 hydrogenated ([Emim]). It was observed that triple alkylated RTILs displayed a voltammetric profile that was surface sensitive on $\mathrm{Au}(\mathrm{hkl})$. Furthermore, [Emmim] $\left[\mathrm{Tf}_{2} \mathrm{~N}\right]$ displayed sharp spikes sensitive to the surface orientation. The hydrogenation of the ring in $\left[\right.$ Emim] $\left[\mathrm{Tf}_{2} \mathrm{~N}\right]$ caused the loosing of the voltammetric surface sensitivity. These results were attributable to a different balance between the ion-ion interactions in the three RTILs. The laser experiments confirmed that the pme in $\mathrm{Au}(\mathrm{hkl}) \mid[\mathrm{Emim}]\left[\mathrm{Tf}_{2} \mathrm{~N}\right]$ follows the trend expected from the work function variations, thus the order was: $\mathrm{Au}(111)>\mathrm{Au}(100)>\mathrm{Au}(110)$, in agreement with previous results obtained in $\left[\right.$ Emmim] $\left[\mathrm{Tf}_{2} \mathrm{~N}\right]$. However, the presence of residual water may have a disturbing role in the interfacial properties of RTILs, not well understood, hindering the determination of the pme in $[\mathrm{Bmmim}]\left[\mathrm{Tf}_{2} \mathrm{~N}\right]$. Rigorous control of the water content and extremely dry conditions would be necessary to obtain better reproducible and reliable results.

Pt(111)|RTIL interface was also investigated and compared with Au(hkl)|RTIL. Pt(111) shows higher affinity by the RTIL than $\mathrm{Au}(\mathrm{hkl})$, i.e., the RTILs interacts with Pt stronger than with $\mathrm{Au}$, displaying a marked hysteresis of the potential laser response towards the applied potential direction. Interestingly, this hysteresis behavior depends on the cation nature of the RTIL. It was found that triple alkylated cation increases the hysteresis in comparison with the double alkylated one (Emim). Thus, the cation structure also affects the dynamics of solvent structuration on $\operatorname{Pt}(111)$. The 
voltammetric profile, however, was always featureless and did not provide relevant characterization information.

$\mathrm{Au}(\mathrm{hkl}) \mid \mathrm{DES}$ was also investigated since results obtained in RTILs proved that Au(hkl) are suitable surface electrodes to investigate the interfacial properties of very different solvents. The voltammetric profiles of $\mathrm{Au}(\mathrm{hkl}) \mid \mathrm{DES}$ were surface sensitive, providing characteristic peaks and sharp spikes for $\mathrm{Au}(111)$ and $\mathrm{Au}(100)$. The absence of spikes in the $\mathrm{Au}(110)$ voltammogram was attributed to the fact that long terrace domains are necessary to induce order-disorder transition of the DES adsorbed on Au(hkl). The laser experiment do not provide a measure of the pme in DES media. Instead of that, a very complex laser response dependent on the surface orientation was obtained. These results induce us to believe that this response was mainly dominated by the high concentration of chloride in the media in addition to the rest of species of the DES. In conclusion, DES are very complex electrolytes and require deeper research to understand their interfacial properties.

\section{CONFLICT OF INTEREST}

The authors declare no conflict of interest.

\section{ACKNOWLEDGEMENTS}

Financial support from MINECO through projects CTQ2016-76221-P (AEI/FEDER, UE) and TEC2017-85059-C3-2R (AEI/FEDER, UE) are greatly acknowledged. P. Sebastian also acknowledges MECD for FPU grant. 


\section{REFERENCES}

[1] M. Armand, F. Endres, D.R. MacFarlane, H. Ohno, B. Scrosati, Ionic-liquid materials for the electrochemical challenges of the future, Nat. Mater. 8 (2009) 621-629. doi:10.1038/nmat2448.

[2] M.C. Buzzeo, R.G. Evans, R.G. Compton, Non-Haloaluminate Room-Temperature Ionic Liquids in Electrochemistry-A Review, ChemPhysChem. 5 (2004) 1106-1120. doi:10.1002/cphc.200301017.

[3] Y.-Z. Su, Y.-C. Fu, Y.-M. Wei, J.-W. Yan, B.-W. Mao, The Electrode/Ionic Liquid Interface: Electric Double Layer and Metal Electrodeposition, ChemPhysChem. 11 (2010) 2764-2778. doi:10.1002/cphc.201000278.

[4] Q. Zhang, Q. Wang, S. Zhang, X. Lu, X. Zhang, Electrodeposition in Ionic Liquids, ChemPhysChem. 17 (2016) 335-351. doi:10.1002/cphc.201500713.

[5] R. Hayes, G.G. Warr, R. Atkin, Structure and Nanostructure in Ionic Liquids, Chem. Rev. 115 (2015) 6357-6426. doi:10.1021/cr500411q.

[6] E.L. Smith, A.P. Abbott, K.S. Ryder, Deep Eutectic Solvents (DESs) and Their Applications, Chem. Rev. 114 (2014) 11060-11082. doi:10.1021/cr300162p.

[7] H. Matsumoto, M. Yanagida, K. Tanimoto, M. Nomura, Y. Kitagawa, Y. Miyazaki, Highly Conductive Room Temperature Molten Salts Based on Small Trimethylalkylammonium Cations and Bis(trifluoromethylsulfonyl)imide, Chem. Lett. 29 (2000) 922-923. doi:10.1246/cl.2000.922.

[8] H. Matsumoto, T. Matsuda, Y. Miyazaki, Room Temperature Molten Salts Based on Trialkylsulfonium Cations and Bis(trifluoromethylsulfonyl)imide, Chem. Lett. 29 (2000) 1430-1431. doi:10.1246/cl.2000.1430.

[9] M. V Fedorov, A.A. Kornyshev, Ionic Liquids at Electrified Interfaces, Chem. Rev. 114 (2014) 2978-3036. doi:10.1021/cr400374x.

[10] H. Tokuda, K. Hayamizu, K. Ishii, M.A.B.H. Susan, M. Watanabe, Physicochemical Properties and Structures of Room Temperature Ionic Liquids. 2. Variation of Alkyl Chain Length in Imidazolium Cation, J. Phys. Chem. B. 109 (2005) 6103-6110. doi:10.1021/jp044626d. 
[11] K. Dong, S. Zhang, Hydrogen Bonds: A Structural Insight into Ionic Liquids, Chem. - A Eur. J. 18 (2012) 2748-2761. doi:10.1002/chem.201101645.

[12] J. Clavilier, R. Faure, G. Guinet, R. Durand, Preparation of Monocrystalline Pt Microelectrodes and Electrochemical Study of the Plane Surfaces Cut in the Direction of the (111) and (110) Planes, J.Electroanal.Chem. 107 (1980) 205-209. doi:10.1016/S0022-0728(79)80022-4.

[13] V. Climent, J.M. Feliu, Thirty years of platinum single crystal electrochemistry, J. Solid State Electrochem. 15 (2011) 1297-1315. doi:10.1007/s10008-011-1372-1.

[14] Y.-C. Fu, Y.-Z. Su, D.-Y. Wu, J.-W. Yan, Z.-X. Xie, B.-W. Mao, Supramolecular Aggregation of Inorganic Molecules at Au(111) Electrodes under a Strong Ionic Atmosphere, J. Am. Chem. Soc. 131 (2009) 14728-14737. doi:10.1021/ja902373q.

[15] F. Buchner, K. Forster-Tonigold, B. Uhl, D. Alwast, N. Wagner, H. Farkhondeh, A. Groß, R.J. Behm, Toward the Microscopic Identification of Anions and Cations at the Ionic Liquid|Ag(111) Interface: A Combined Experimental and Theoretical Investigation, ACS Nano. 7 (2013) 7773-7784. doi:10.1021/nn4026417.

[16] Y.-Z. Su, Y.-C. Fu, J.-W. Yan, Z.-B. Chen, B.-W. Mao, Double Layer of Au(100)/Ionic Liquid Interface and Its Stability in Imidazolium-Based Ionic Liquids, Angew. Chemie Int. Ed. 48 (2009) 5148-5151. doi:10.1002/anie.200900300.

[17] T. Pajkossy, C. Müller, T. Jacob, The metal-ionic liquid interface as characterized by impedance spectroscopy and: In situ scanning tunneling microscopy, Phys. Chem. Chem. Phys. 20 (2018) 21241-21250. doi:10.1039/c8cp02074d.

[18] Y. Zhong, J. Yan, M. Li, L. Chen, B. Mao, The Electric Double Layer in an Ionic Liquid Incorporated with Water Molecules: Atomic Force Microscopy Force Curve Study, ChemElectroChem. 3 (2016) 2221-2226. doi:10.1002/celc.201600177.

[19] T. Cui, A. Lahiri, T. Carstens, N. Borisenko, G. Pulletikurthi, C. Kuhl, F. Endres, Influence of Water on the Electrified Ionic Liquid/Solid Interface: A Direct Observation of the Transition from a Multilayered Structure to a Double-Layer Structure, J. Phys. Chem. C. 120 (2016) 9341-9349. doi:10.1021/acs.jpcc.6b02549.

[20] M. Gnahm, D.M. Kolb, The purification of an ionic liquid, J. Electroanal. Chem. 651 (2011) 250-252. doi:https://doi.org/10.1016/j.jelechem.2010.11.019.

[21] G. Feng, X. Jiang, R. Qiao, A.A. Kornyshev, Water in Ionic Liquids at Electrified Interfaces: The Anatomy of Electrosorption, ACS Nano. 8 (2014) 11685-11694. doi:10.1021/nn505017c. 
[22] J. Friedl, I.I.E. Markovits, M. Herpich, G. Feng, A.A. Kornyshev, U. Stimming, Interface between an Au(111) Surface and an Ionic Liquid: The Influence of Water on the Double-Layer Capacitance, ChemElectroChem. 4 (2017) 216-220. doi:10.1002/celc.201600557.

[23] P. Bonhôte, A.-P. Dias, N. Papageorgiou, K. Kalyanasundaram, M. Grätzel, Hydrophobic, Highly Conductive Ambient-Temperature Molten Salts, Inorg. Chem. 35 (1996) 1168-1178. doi:10.1021/ic951325x.

[24] A.P. Sandoval, M.F. Suárez-Herrera, J.M. Feliu, Hydrogen redox reactions in 1-ethyl2,3-dimethylimidazolium bis(trifluoromethylsulfonyl)imide on platinum single crystal electrodes, Electrochem. Commun. 46 (2014) 84-86. doi:https://doi.org/10.1016/j.elecom.2014.06.016.

[25] P. Sebastian, M. Tułodziecki, M.P. Bernicola, V. Climent, E. Gómez, Y. Shao-Horn, J.M. Feliu, Use of CO as a Cleaning Tool of Highly Active Surfaces in Contact with Ionic Liquids: Ni Deposition on Pt(111) Surfaces in IL, ACS Appl. Energy Mater. 1 (2018) 4617-4625. doi:10.1021/acsaem.8b00776.

[26] A.M. Navarro-Suárez, J.C. Hidalgo-Acosta, L. Fadini, J.M. Feliu, M.F. Suárez-Herrera, Electrochemical Oxidation of Hydrogen on Basal Plane Platinum Electrodes in Imidazolium Ionic Liquids, J. Phys. Chem. C. 115 (2011) 11147-11155. doi:10.1021/jp201886m.

[27] Y.-Y. Yang, L.-N. Zhang, M. Osawa, W.-B. Cai, Surface-Enhanced Infrared Spectroscopic Study of a CO-Covered Pt Electrode in Room-Temperature Ionic Liquid, J. Phys. Chem. Lett. 4 (2013) 1582-1586. doi:10.1021/jz400657t.

[28] M. Papasizza, A. Cuesta, In Situ Monitoring Using ATR-SEIRAS of the Electrocatalytic Reduction of CO2 on Au in an Ionic Liquid/Water Mixture, ACS Catal. 8 (2018) 63456352. doi:10.1021/acscatal.8b00977.

[29] D.M. Kolb, Reconstruction phenomena at metal-electrolyte interfaces, in: Prog. Surf. Sci., 1996: pp. 109-173. doi:https://doi.org/10.1016/0079-6816(96)00002-0.

[30] N. García-Aráez, V. Climent, J.M. Feliu, Evidence of water reorientation on model electrocatalytic surfaces from nanosecond-laser-pulsed experiments, J. Am. Chem. Soc. 130 (2008) 3824-3833. doi:10.1021/ja0761481.

[31] V. Climent, B.A. Coles, R.G. Compton, Laser-Induced Potential Transients on a Au(111) Single-Crystal Electrode. Determination of the Potential of Maximum Entropy of Double-Layer Formation, J. Phys. Chem. B. 106 (2002) 5258-5265. 
doi:10.1021/jp020054q.

[32] P. Sebastián, V. Climent, J.M. Feliu, Characterization of the interfaces between Au(hkl) single crystal basal plane electrodes and [Emmim][Tf2N] ionic liquid, Electrochem. Commun. 62 (2016) 44-47.

[33] P. Sebastián, A.P. Sandoval, V. Climent, J.M. Feliu, Study of the interface Pt(111)/ [Emmim][NTf2] using laser-induced temperature jump experiments, Electrochem. Commun. 55 (2015) 39-42.

[34] A.P. Abbott, D. Boothby, G. Capper, D.L. Davies, R.K. Rasheed, Deep Eutectic Solvents Formed between Choline Chloride and Carboxylic Acids: Versatile Alternatives to Ionic Liquids, J. Am. Chem. Soc. 126 (2004) 9142-9147. doi:10.1021/ja048266j.

[35] C. Du, B. Zhao, X.-B. Chen, N. Birbilis, H. Yang, Effect of water presence on choline chloride-2urea ionic liquid and coating platings from the hydrated ionic liquid, Sci. Rep. 6 (2016) 29225. https://doi.org/10.1038/srep29225.

[36] P. Sebastián, R. Martínez-Hincapié, V. Climent, J.M. Feliu, Study of the Pt (111) | electrolyte interface in the region close to neutral $\mathrm{pH}$ solutions by the laser induced temperature jump technique, Electrochim. Acta. 228 (2017) 667-676. doi:https://doi.org/10.1016/j.electacta.2017.01.089.

[37] V. Climent, B.A. Coles, R.G. Compton, Coulostatic Potential Transients Induced by Laser Heating of a Pt(111) Single-Crystal Electrode in Aqueous Acid Solutions. Rate of Hydrogen Adsorption and Potential of Maximum Entropy, J. Phys. Chem. B. 106 (2002) 5988-5996. doi:10.1021/jp020785q.

[38] T. Pajkossy, D.M. Kolb, The interfacial capacitance of Au(100) in an ionic liquid, 1butyl-3-methyl-imidazolium hexafluorophosphate, Electrochem. Commun. 13 (2011) 284-286. doi:https://doi.org/10.1016/j.elecom.2011.01.004.

[39] M. Gnahm, T. Pajkossy, D.M. Kolb, The interface between Au(111) and an ionic liquid, Electrochim. Acta. 55 (2010) 6212-6217. doi:https://doi.org/10.1016/j.electacta.2009.08.031.

[40] C. Müller, S. Vesztergom, T. Pajkossy, T. Jacob, The interface between Au(100) and 1butyl-3-methyl-imidazolium-bis(trifluoromethylsulfonyl)imide, J. Electroanal. Chem. 737 (2015) 218-225. doi:https://doi.org/10.1016/j.jelechem.2014.06.010.

[41] L.G. Lin, Y. Wang, J.W. Yan, Y.Z. Yuan, J. Xiang, B.W. Mao, An in situ STM study on the long-range surface restructuring of $\mathrm{Au}(111)$ in a non-chloroaluminumated ionic 
liquid, Electrochem. Commun. 5 (2003) 995-999.

doi:https://doi.org/10.1016/j.elecom.2003.09.013.

[42] F.A. Hanc-Scherer, C.M. Sánchez-Sánchez, P. Ilea, E. Herrero, Surface-Sensitive Electrooxidation of Carbon Monoxide in Room Temperature Ionic Liquids, ACS Catal. 3 (2013) 2935-2938. doi:10.1021/cs4007364.

[43] N. Garcia-Araez, V. Climent, J. Feliu, Potential-Dependent Water Orientation on Pt(111), Pt(100), and Pt(110), As Inferred from Laser-Pulsed Experiments. Electrostatic and Chemical Effects, J. Phys. Chem. C. 113 (2009) 9290-9304. doi:10.1021/jp900792q.

[44] K. Motobayashi, M. Osawa, Potential-dependent condensation of Water at the Interface between ionic liquid [BMIM][TFSA] and an Au electrode, Electrochem. Commun. 65 (2016) 14-17. doi:10.1016/J.ELECOM.2016.01.018.

[45] Shuai Liu, J. Peng, L. Chen, P. Sebastián, J.M. Feliu, J. Yan, B.W. Mao, Comparative Studies on Electrochemical Interfaces in Ionic Liquids EMMITFSI and EMITFSI by Insitu STM and AFM, Electrochim. Acta. (2019). accepted.

[46] M.F. Suárez-Herrera, M. Costa-Figueiredo, J.M. Feliu, Voltammetry of Basal Plane Platinum Electrodes in Acetonitrile Electrolytes: Effect of the Presence of Water, Langmuir. 28 (2012) 5286-5294. doi:10.1021/la205097p.

[47] S. Baldelli, Surface structure at the ionic liquid-electrified metal interface, Acc. Chem. Res. 41 (2008) 421-431. doi:10.1021/ar700185h.

[48] K. Motobayashi, K. Minami, N. Nishi, T. Sakka, M. Osawa, Hysteresis of PotentialDependent Changes in Ion Density and Structure of an Ionic Liquid on a Gold Electrode: In Situ Observation by Surface-Enhanced Infrared Absorption Spectroscopy, J. Phys. Chem. Lett. 4 (2013) 3110-3114. doi:10.1021/jz401645c.

[49] M. Zhang, L.J. Yu, Y.F. Huang, J.W. Yan, G.K. Liu, D.Y. Wu, Z.Q. Tian, B.W. Mao, Extending the shell-isolated nanoparticle-enhanced Raman spectroscopy approach to interfacial ionic liquids at single crystal electrode surfaces, Chem. Commun. 50 (2014) 14740-14743. doi:10.1039/c4cc06269h.

[50] X. Zhang, Y.X. Zhong, J.W. Yan, Y.Z. Su, M. Zhang, B.W. Mao, Probing double layer structures of $\mathrm{Au}$ (111)-BMIPF 6 ionic liquid interfaces from potential-dependent AFM force curves, Chem. Commun. 48 (2012) 582-584. doi:10.1039/c1cc15463j.

[51] W. Germany, Surface Reconstruction in Electrochemistry :, Electrochim. Acta. 31 (1986) 929-936. doi:https://doi.org/10.1016/0013-4686(86)80005-6. 
[52] P. Sebastián, E. Gómez, V. Climent, J.M. Feliu, Copper underpotential deposition at gold surfaces in contact with a deep eutectic solvent: New insights, Electrochem. Commun. 78 (2017) 51-55.

[53] T.N. Andersen, J.O. 'M. Bockris, Forces involved in the "specific" adsorption of ions on metals from aqueous solution, Electrochim. Acta. 9 (1964) 347-371. doi:10.1016/00134686(64)80042-6.

\section{CAPTIONS}

Scheme 1: Scheme of the imidazolium cation structure: a) cations methylated in C2 position and b) hydrogenated cation in $\mathrm{C} 2$ position. c) $\mathrm{Tf}_{2} \mathrm{~N}$ anion (right side). d) choline chloride: urea DES structure.

Figure 1. Cyclic voltammetries of the interface between $\mathrm{Au}(\mathrm{hkl})$ in contact with $\mathrm{A}$ ) $[$ Emmim $]\left[\mathrm{Tf}_{2} \mathrm{~N}\right]$, B) $[$ Bmmim $]\left[\mathrm{Tf}_{2} \mathrm{~N}\right]$ and C) $\left[\mathrm{Emim}^{-}\right]\left[\mathrm{Tf}_{2} \mathrm{~N}\right]$. Pseudo-capacitive voltammetric region. Scan rate: $50 \mathrm{mV} / \mathrm{s}$.

Figure 2. Cyclic voltammetries of the interface between $\mathrm{Au}(\mathrm{hkl})$ in contact with $\mathrm{A}$ )

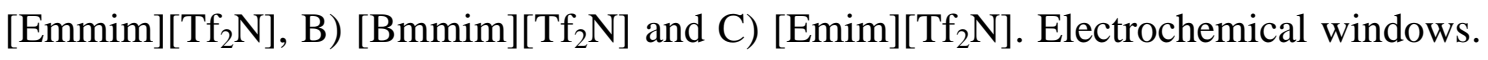
Scan rate: $50 \mathrm{mV} / \mathrm{s}$.

Figure 3. Laser induced potential transients and pme location for the interface between A) $\mathrm{Au}(111) \mid\left[\right.$ Emim] $\left.\left[\mathrm{Tf}_{2} \mathrm{~N}\right], \mathrm{B}\right) \mathrm{Au}(100) \mid[\mathrm{Emim}]\left[\mathrm{Tf}_{2} \mathrm{~N}\right]$ and C) $\mathrm{Au}(110) \mid[\mathrm{Emim}]\left[\mathrm{Tf}_{2} \mathrm{~N}\right]$. Energy beam: 2-5mJ. Eapp in the $\mathrm{z}$ axis means applied electrode potential.

Figure 4. Laser induced potential transients for the interface between A) Au(111)| [Emmim] $\left[\mathrm{Tf}_{2} \mathrm{~N}\right]$, B) $\mathrm{Au}(111) \mid\left[\mathrm{Bmmim}_{[}\right]\left[\mathrm{Tf}_{2} \mathrm{~N}\right]$ and C) $\left.\mathrm{Au}(111) \mid[\mathrm{Emim}]\left[\mathrm{Tf}_{2} \mathrm{~N}\right] . \mathrm{D}\right)$ pme location (indicated by the arrows) in relation to the voltammetric features for the interfaces between $\mathrm{Au}(111) \mid[$ cation $]\left[\mathrm{Tf}_{2} \mathrm{~N}\right]($ cation $=[$ Emmim $],[$ Bmmim $]$ and $[$ Emim] $)$. Energy beam: 2-5mJ. Eapp in the $\mathrm{z}$ axis means applied electrode potential. 
Figure 5. Cyclic voltammetries of the interface between $\mathrm{Pt}(111)$ in contact with A) $[$ Emmim] $\left.]\left[\mathrm{Tf}_{2} \mathrm{~N}\right], \mathrm{B}\right)[\mathrm{Bmmim}]\left[\mathrm{Tf}_{2} \mathrm{~N}\right]$ and $\left.\mathrm{C}\right)\left[\right.$ Emim $\left.\left._{[}\right] \mathrm{Tf}_{2} \mathrm{~N}\right]$. Electrochemical windows. Scan rate: $50 \mathrm{mV} / \mathrm{s}$.

Figure 6. Laser induced potential transients (from positive to negative applied potentials) and slopes proportional to the thermal coefficients for the interfaces: A) $\operatorname{Pt}(111) \mid[$ Emmim] $\left.]\left[\mathrm{Tf}_{2} \mathrm{~N}\right], \mathrm{B}\right) \operatorname{Pt}(111) \mid\left[\right.$ Bmmim] $\left[\mathrm{Tf}_{2} \mathrm{~N}\right]$ and C) $\operatorname{Pt}(111) \mid[$ Emim $]\left[\mathrm{Tf}_{2} \mathrm{~N}\right]$. Energy beam: 2-3mJ.

Figure 7: Cyclic voltammograms at 50mV/s (left site) and potential laser transients (right site) for the interface $\mathrm{Au}(\mathrm{hkl}) \mid \mathrm{DES}$ : A)Au(111), B) $\mathrm{Au}(100)$ and C) $\mathrm{Au}(110)$. 


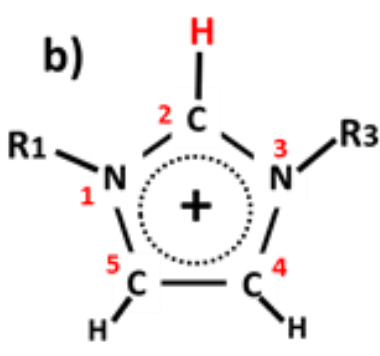<smiles>O=S(=O)(NS(=O)(=O)C(F)(F)F)C(F)(F)F</smiles>

[ $\mathrm{Tf}_{2} \mathrm{~N}$ ]

\section{R1,R2: Methyl R3: Ethyl or Butyl}

d)<smiles>CC[N+](C)(CC)CCO</smiles>

\section{Scheme 1}
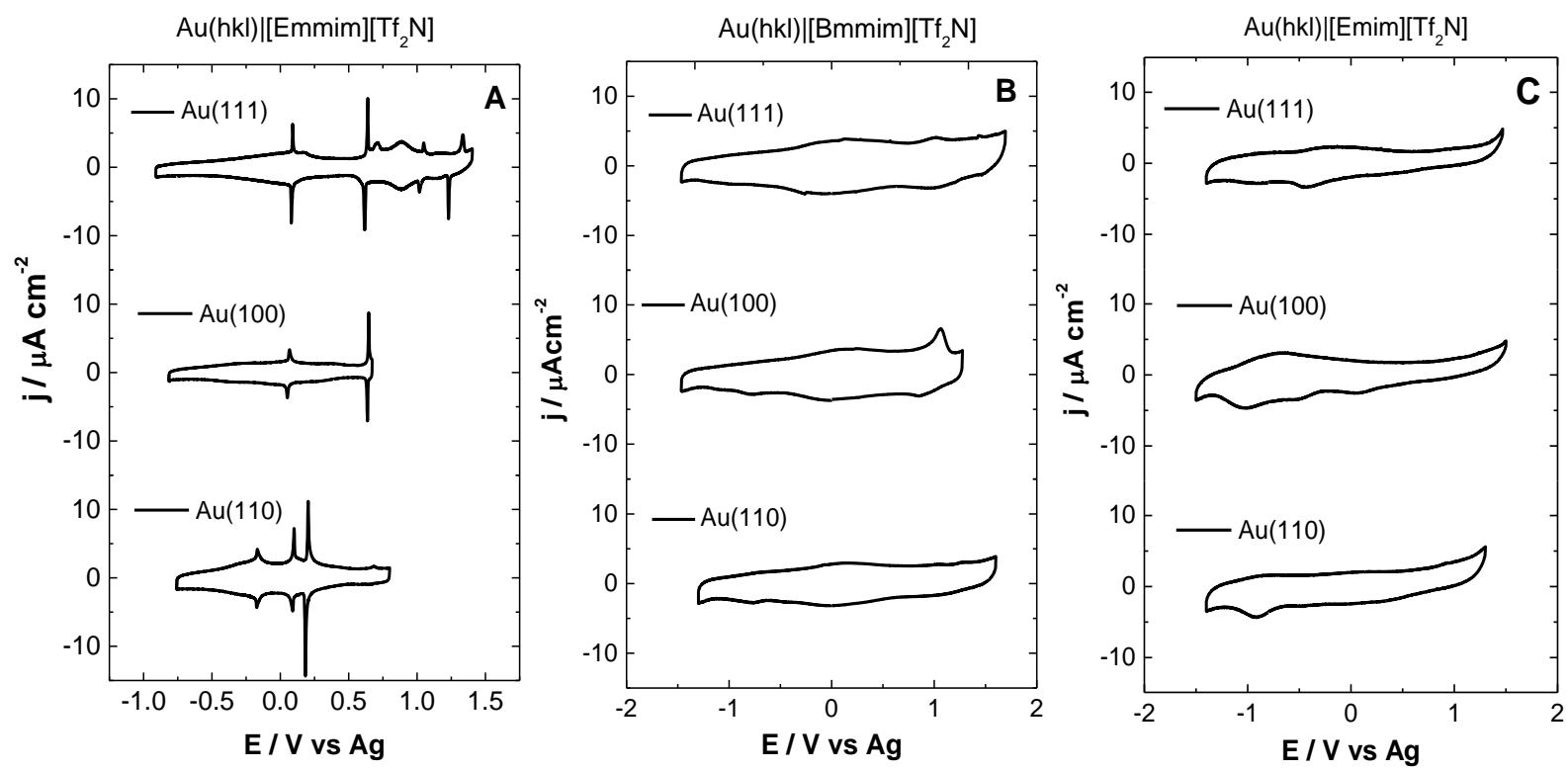

Figure 1 

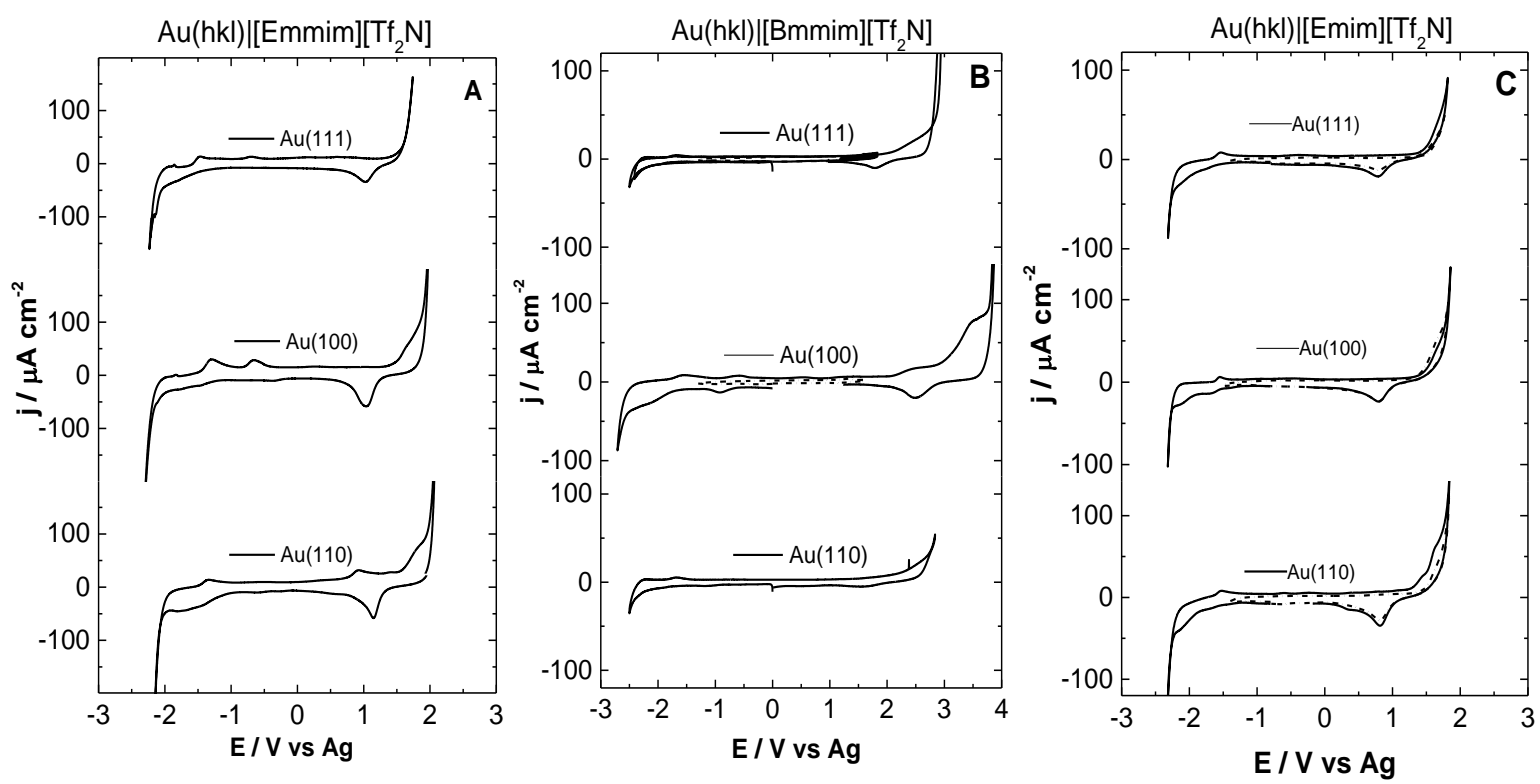

Figure 2 

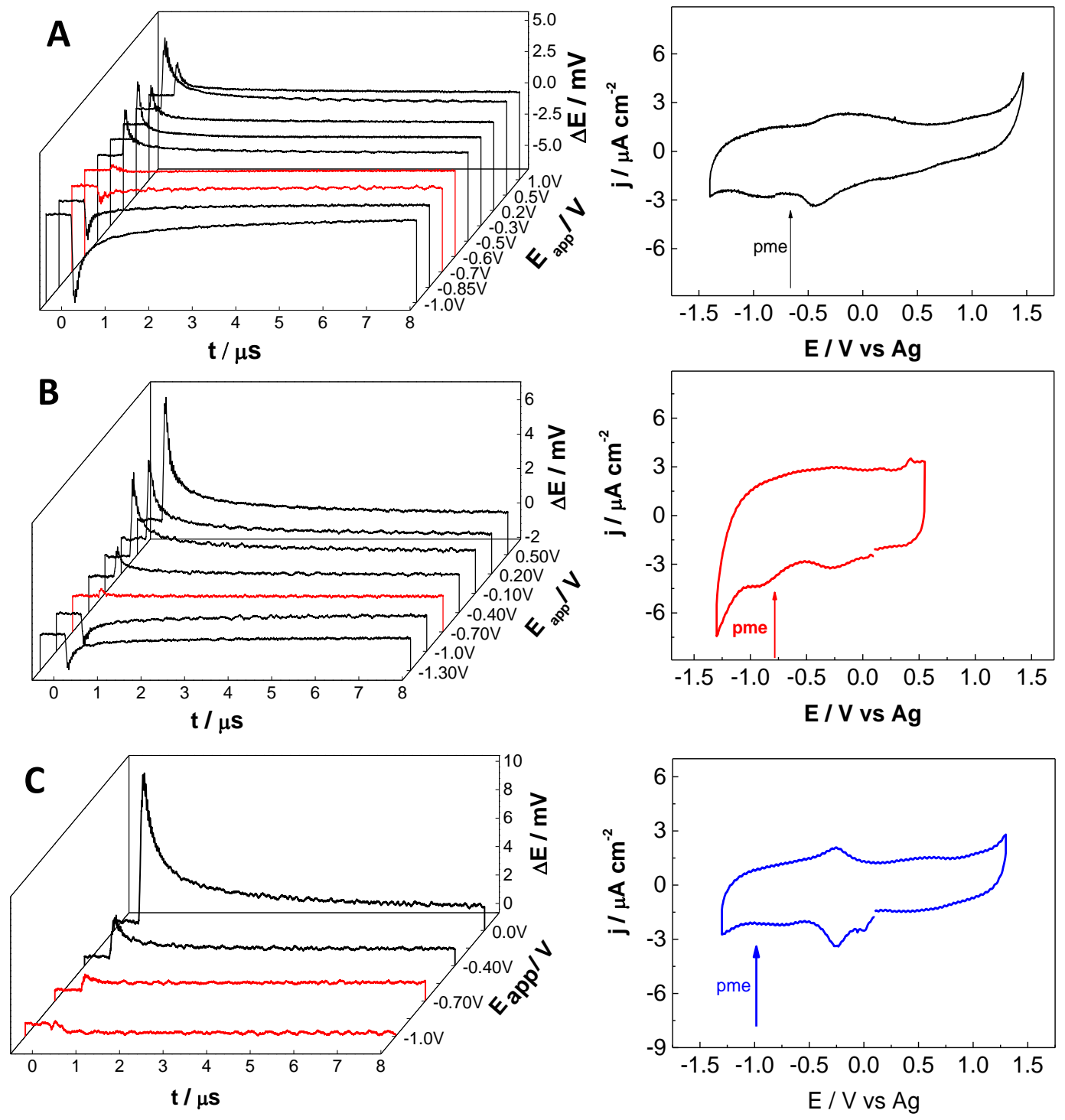

Figure 3 

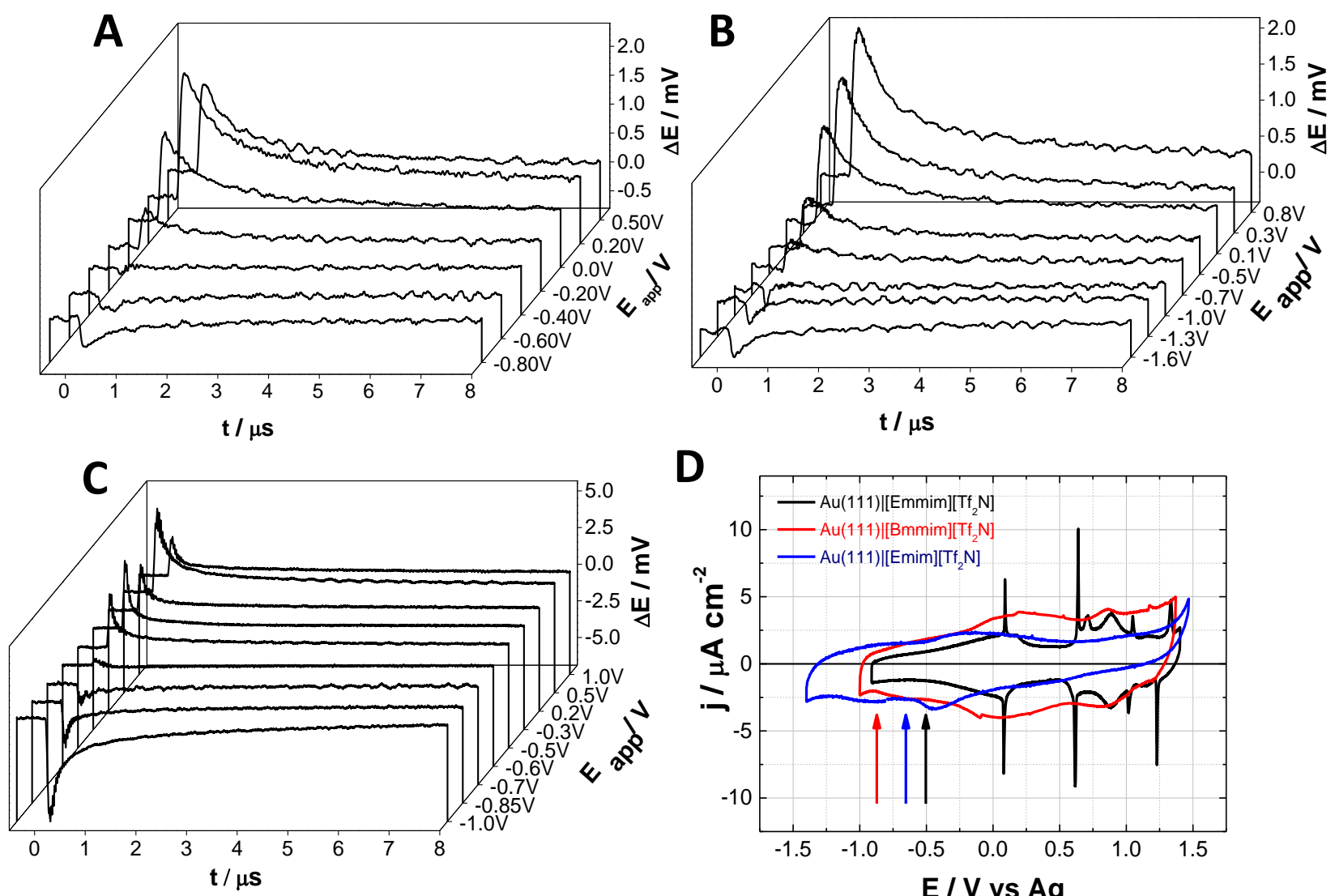

D

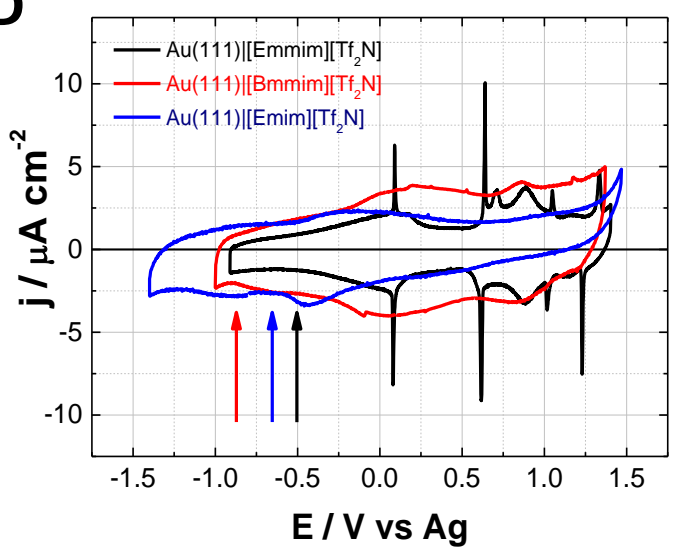

Figure 4 

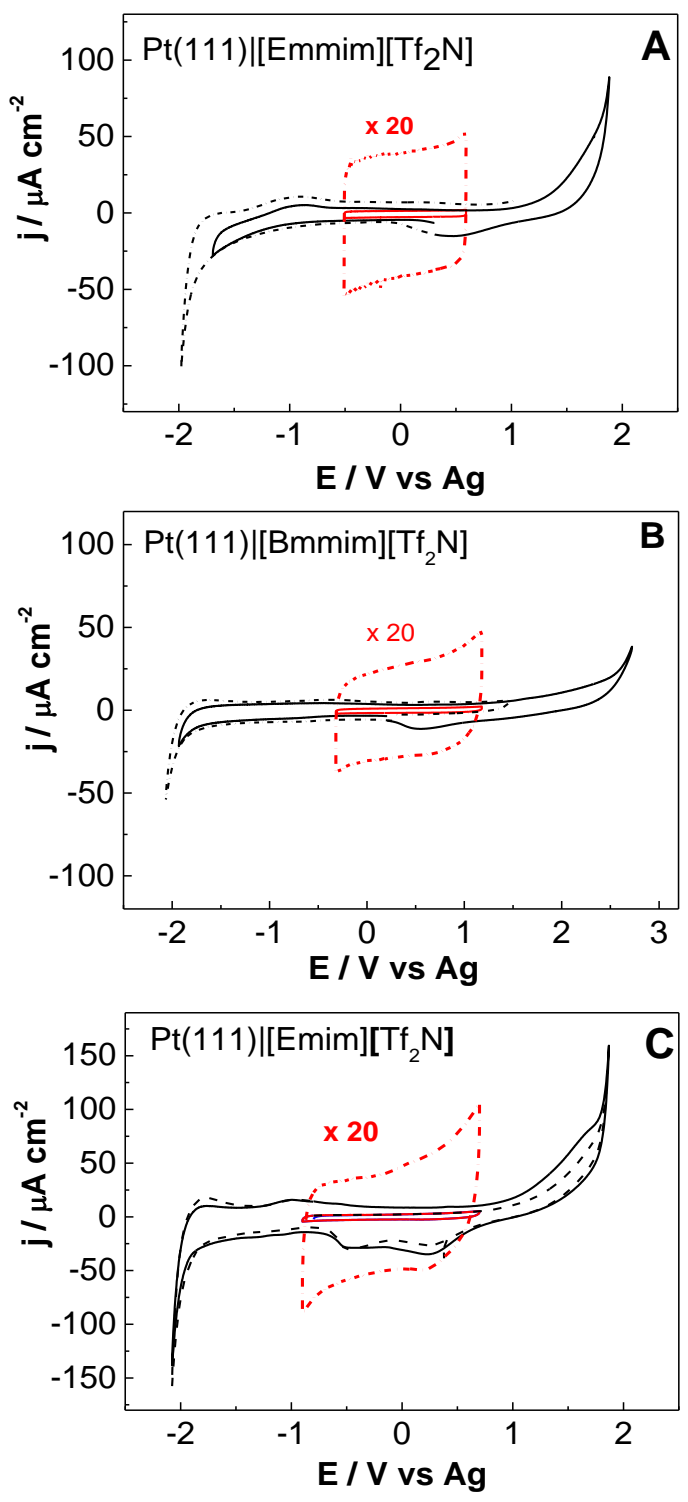

Figure 5 

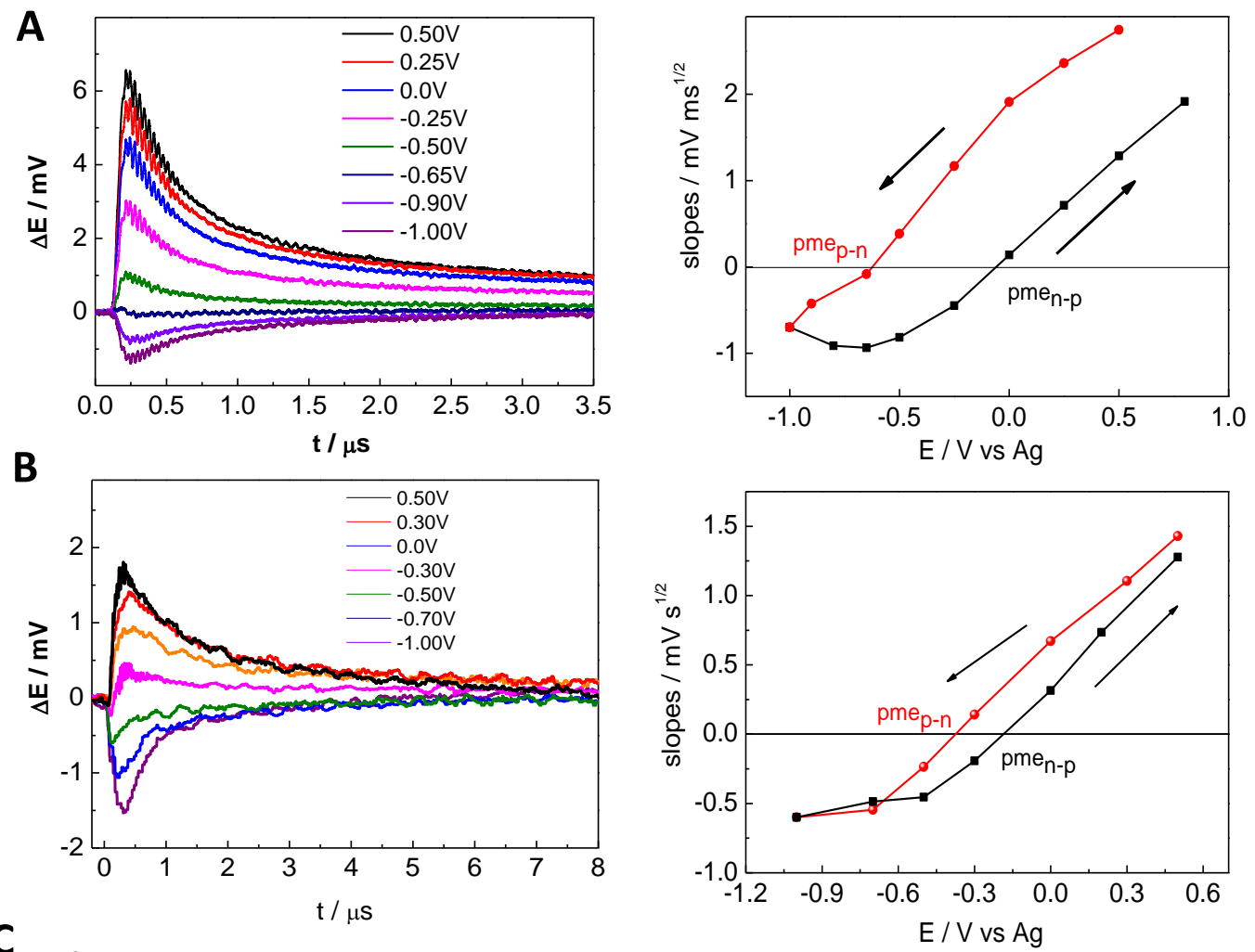

C
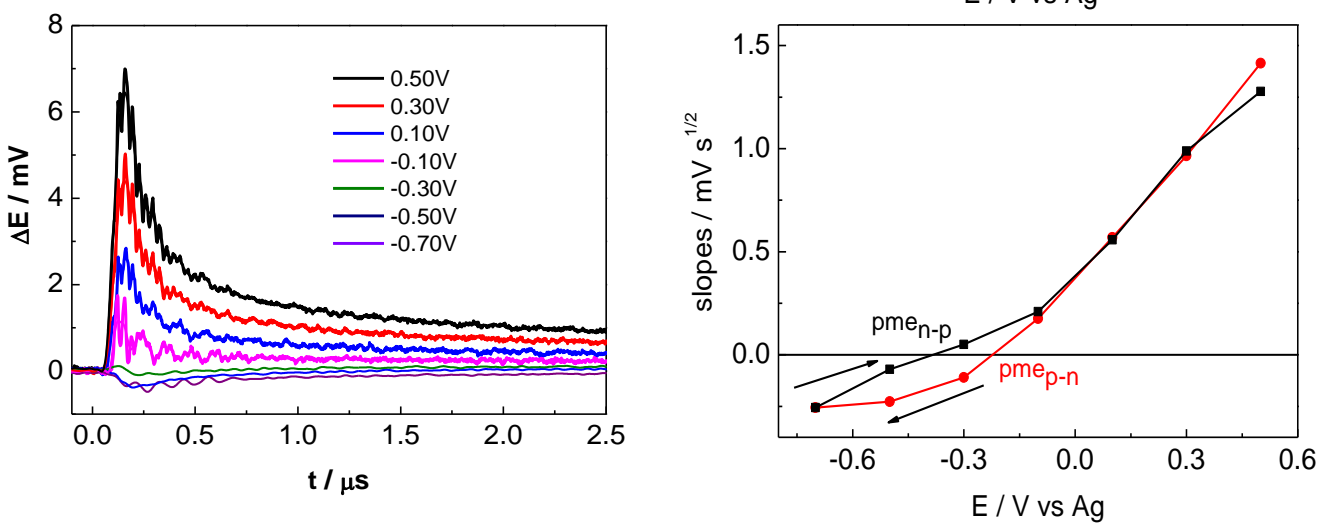

Figure 6 

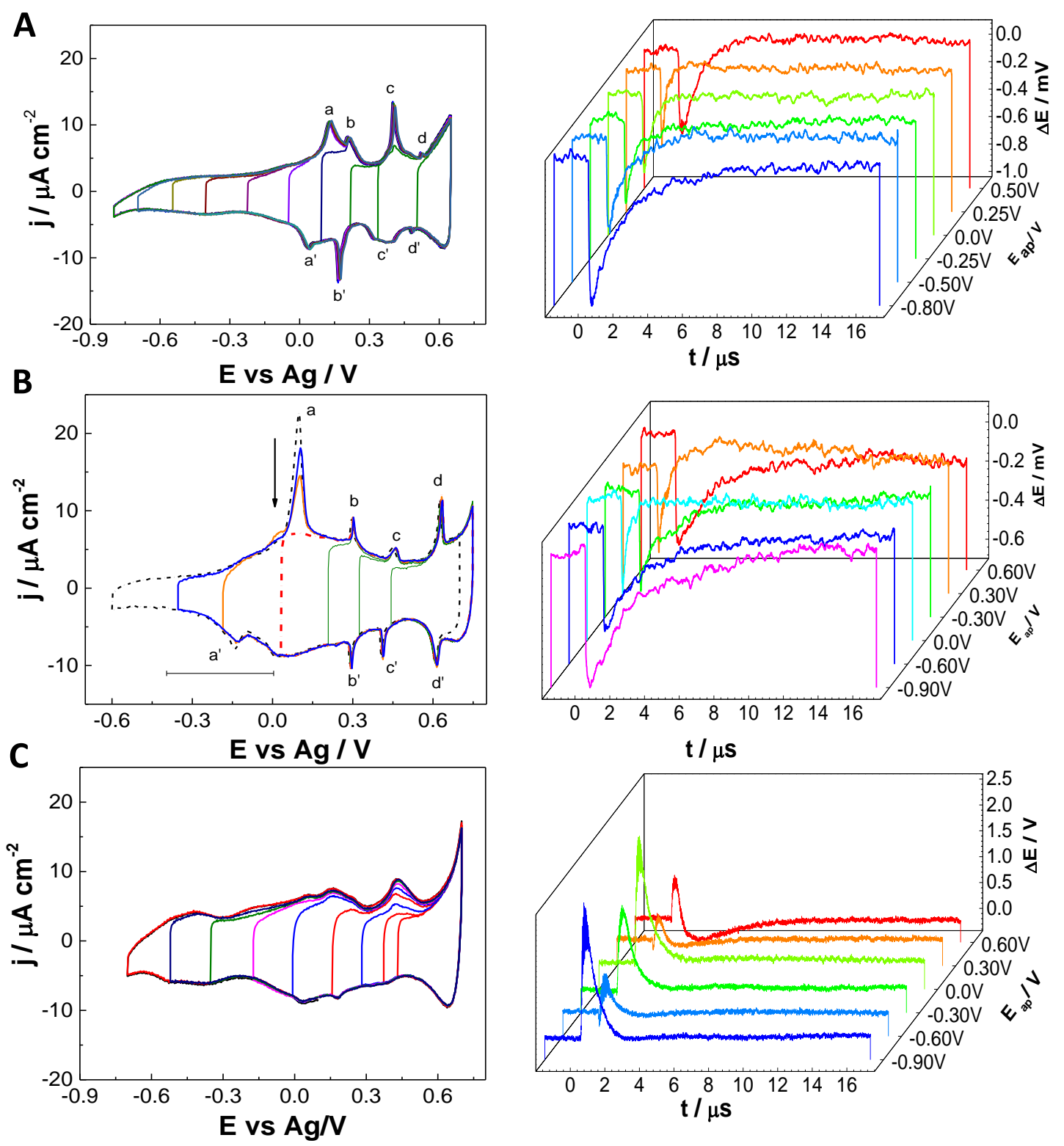

Figure 7 